\title{
Who takes the medicine? Adherence to antiretroviral therapy in Southern Ethiopia
}

\author{
This article was published in the following Dove Press journal: \\ Patient Preference and Adherence \\ 29 October 2015 \\ Number of times this article has been viewed
}

\author{
Wondu Teshome' \\ Mihretu Belayneh' \\ Mathewos Moges' \\ Misganu Endriyas ${ }^{2}$ \\ Emebet Mekonnen² \\ Sinafiksh Ayele ${ }^{2}$ \\ Tebeje Misganaw ${ }^{2}$ \\ Mekonnen Shiferaw ${ }^{2}$ \\ Palanivel Chinnakali ${ }^{3}$ \\ Sven Gudmund Hinderaker ${ }^{4}$ \\ Ajay MV Kumar ${ }^{5}$ \\ 'School of Public and Environmental \\ Health, College of Medicine and \\ Health Sciences, Hawassa University, \\ Hawassa, Ethiopia; ${ }^{2}$ Research \\ Technology Transfer Process Unit, \\ SNNP Regional Health Bureau, \\ Hawassa, Ethiopia; ${ }^{3}$ Department \\ of Preventive and Social Medicine, \\ Jawaharlal Institute of Post-graduate \\ Medical Education and Research, \\ Puducherry, India; ${ }^{4}$ Centre for \\ International Health, University \\ of Bergen, Bergen, Norway; \\ ${ }^{5}$ The International Union Against \\ Tuberculosis and Lung Disease, \\ South-East Asia Regional Office, \\ New Delhi, India
}

Correspondence: Wondu Teshome PO Box 898, Hawassa, Ethiopia Tel +25। 9l I76 I805

Email wondu_teshome@yahoo.com
Background: Treatment adherence is critical for the success of antiretroviral therapy (ART) for people living with HIV. There is limited representative information on ART drug adherence and its associated factors from Southern Ethiopia. We aimed at estimating the level of adherence to ART among people living with HIV and factors associated with it in 20 randomly selected ART clinics of Southern Ethiopia.

Methods: In this cross-sectional study, we interviewed consecutive HIV patients on first-line antiretroviral regimen attending the clinics in June 2014 using a pretested and structured questionnaire. For measuring adherence, we used 4-day recall method based on "The AIDS Clinical Trial Group adherence assessment tool". Patients were classified as "Incomplete adherence" if they missed any of the doses in the last 4 days. Data were singly entered using EpiData and descriptive analysis, and unadjusted odds ratios were calculated using EpiDataStat software. Multivariate logistic regression analysis was performed using Stata v12.0.

Results: Of 974 patients interviewed, 539 (56\%) were females, and mean age was 35 years. The proportion of patients with incomplete adherence was $13 \%$ (95\% confidence interval: $11 \%-15 \%)$. In multivariate analysis, factors significantly associated with incomplete adherence included young age, being Protestant Christian, consuming alcohol, being single, and being a member of an HIV association. Psychosocial factors like stigma, depression, and satisfaction to care were not associated with incomplete adherence in the current context.

Conclusion: The overall adherence to ART was good. However, there were certain subgroups with incomplete adherence who need special attention. The health care providers (especially counselors) need to be aware of these subgroups and tailor their counseling to improve adherence among these groups. Exploratory qualitative studies may help uncover the exact reasons for incomplete adherence.

Keywords: operational research, SORT IT, treatment compliance

\section{Background}

Globally, there were an estimated 12.9 million people living with HIV on antiretroviral therapy (ART) in 2013, and of these, 9.1 million (71\%) were in Africa. ${ }^{1}$ Access to ART has expanded significantly in the last decade and has saved hundreds of thousands of lives. The impact of ART on HIV disease progression and transmission depends on many factors, one of which is adherence to ART. Adherence assessment has been included as one of the five early warning indicators for HIV drug resistance in countries scaling up ART program. ${ }^{2}$ Studies on the benefits of treatment adherence have found that more than $95 \%$ adherence is required for effective and sustained viral suppression. ${ }^{3,4}$ Systematic reviews have reported that adherence to ART ranged from 55\% (95\% CI [confidence interval]: 49\%-62\%) in developed countries to $77 \%$ (95\% CI: $68 \%-85 \%$ ) in developing countries. This indicates better adherence in developing countries than developed ones. ${ }^{5}$ Use of fixed dose combinations, ${ }^{3}$ as well as factors 
such as sex, depression, social support, pill burden, payment for drugs, adverse drug effects, malnutrition have been shown influence the adherence. ${ }^{5,6}$

In Ethiopia, HIV/AIDS has been and still is a big challenge to the health system, as elsewhere in most sub-Saharan African countries. With an estimated HIV prevalence of $1.2 \%(95 \%$ CI: $1.1 \%-1.4 \%$ ), HIV/AIDS is one of the major causes of deaths. ${ }^{7}$ Previous studies from Ethiopia have reported ART adherence levels ranging from $73 \%$ to $96 \% .^{6,8-11}$ Most of these were conducted in urban areas, had small sample size, were limited to one or two facilities, and were mostly reported from Northern Ethiopia. There is limited representative information from Southern Ethiopia. While each study focused on selected factors affecting adherence, no single study examined all the factors (like demographic, behavioral and clinical characteristics, social support, access to health facilities, depression, stigma, and knowledge on ART) comprehensively together. Therefore, we aimed at determining the level of adherence to first-line ART among HIV infected patients enrolled into HIV care in Southern Ethiopia and to identify various factors associated with adherence to first-line ART.

\section{Methods}

\section{Study design}

This was a cross-sectional study involving a structured interview of HIV patients attending ART clinics (exit interview).

\section{Study setting}

Ethiopia is located in East Africa (population: 88 million) and is divided into eleven administrative regions. Southern Nations, Nationalities and Peoples' Regional State (SNNPRS), with an estimated population of 16.5 million, is the third largest region and represents approximately $20 \%$ of the country's population. Approximately $93 \%$ of the populations in SNNPRS live in rural areas. ${ }^{12}$ The prevalence of HIV infection among adults in the region was $0.9 \%$, lower than the national average. ${ }^{7}$

In 2014, there were a total of 22 public hospitals, 448 public health centers, and 3,340 health posts in SNNPRS. The potential health service coverage, defined as population living within $10 \mathrm{~km}$ of a primary heath care unit in 2010, is estimated to be $93 \%$. In total, 22 hospitals and 141 health centers were providing ART care in the region. Most HIV-infected patients receive care from government health facilities. ${ }^{13}$

The National HIV programme has a vertical structure, and all ART clinics are staffed by trained and certified health workers. The national guidelines for starting ART including the use of prophylactic medications like cotrimoxazole preventive therapy and isoniazid preventive therapy are based on WHO (World Health Organization) 2010 guidelines. ${ }^{14}$

Patients are started on first-line ART regimen consisting of (tenofovir or zidovudine)/lamivudine/(nevirapine or efavirenz) twice a day or once a day depending on the regimen. Patients receiving ART are expected to attend the ART clinic monthly for the first 3-6 months and once in 2 months after that (once assessed as clinically stable). All patients are counseled about the benefits of adherence to treatment and other behavioral modifications during their routine visits to the ART centers by the adherence counselors. ${ }^{15}$ ART and all laboratory investigations are provided free of cost to patients at all health facilities.

\section{Study population}

All consecutive HIV-infected adults aged 15 years and above registered for ART in selected health facilities and attending the ART clinic in June 2014. In total, 12 hospitals and 8 heath centers providing ART services were randomly selected using random number generator on Excel. We included only HIV-infected adults on first-line ART regimen in these selected facilities.

\section{Definition of adherence}

We used 4-day recall method for measuring adherence. Patients were asked whether they had taken their medications each day during the past 4 days. If none of the doses was missed during the past 4 days, adherence was considered "complete". Patients were classified as "Incomplete adherence" if they missed any of the doses in the 4 days period.

Several methods including patient self-reporting, pill counts, audits of pharmacy refill records, drug level measurements in blood, and viral load testing have been tried to measure adherence. Each method has its own advantages and challenges. ${ }^{16}$ Drug level measurements are expensive and cannot be used in routine programmatic settings. Access to viral load measurements is not yet a reality in Ethiopia. Studies using self-reported adherence have been documented to correlate with viral load. ${ }^{17}$ Different periods of recall, ranging from 2 to 365 days ( mode $=7$ days), have been used in previous studies. ${ }^{17}$ The AIDS Clinical Trials Group adherence instrument uses a 4-day recall period and has been shown to correlate well with viral load. ${ }^{18}$ Other studies have also shown that brief self-report measures of antiretroviral adherence can be robust in measuring adherence to treatment. ${ }^{17}$ Since the duration of recall is less, we used this method to minimize recall limitation. 


\section{Data variables and data collection}

Variables included age, sex, education, marital status, place of residence, alcohol use, type of treatment regimen and frequency of dosing, assistance to remember medication, perceived stigma, level of depression, knowledge on ART, satisfaction about care, and adherence to ART. We adapted "the Berger HIV Stigma Scale"19 for assessing stigma related to HIV/AIDS. Depression was assessed using a modified version of Beck Depression Inventory. ${ }^{20}$

Interviews with study participants were conducted at ART clinics by comprehensive HIV-care-trained and certified health workers. The selected data collectors were provided 3 days training, including class sessions and pretesting the data collection formats. To avoid socially desirable responses, the patients were interviewed by health workers working in a different health facility.

\section{Analysis and statistics}

Data were singly entered and analyzed using EpiData software (version 3.1 for data entry and version 2.2.2.182 for analysis; EpiData association, Odense, Denmark). Incomplete adherence to ART was expressed as proportion with $95 \%$ CI. Unadjusted odds ratios were calculated to assess possible association between incomplete adherence and the independent variables. Variables significant at $P$-value of less than 0.2 in unadjusted analysis were included in multivariate analysis. Adjusted odds ratios using multivariate logistic regression were calculated to assess the independent effect of factors on incomplete adherence, and a $P$-value of less than 0.05 was considered statistically significant. The multivariate regression analysis was performed using Stata v12.0 (Stata Corporation, Release 12, College Station, TX, USA).

\section{Ethics}

Permission to carry out the study was obtained from SNNPR Health Bureau. Local ethics approval was obtained from the Institutional Review Board of the SNNPR Health Bureau. The study was also approved by the Ethics Advisory Group of the International Union Against Tuberculosis and Lung Disease, Paris, France. Informed consent for the study was obtained from all participants.

\section{Results}

A total of 1,263 patients were interviewed during the study period. Complete information was available for 974 (77\%) patients, and these were included in the final analysis. Of 289 patients excluded, information on age and sex was available for 77 patients, and there was no difference in distribution compared to those included in the analysis.

Sociodemographic and behavioral characteristics of HIV-infected patients on ART are shown in Table 1. The mean age (standard deviation) of the participants was 35 (9) years, and $539(55.5 \%)$ were females. Most participants (61.2\%) had no formal education. Fifteen percent of the participants reported that they consumed alcohol in the past 1 month.

Health facility access, social support, and treatment characteristics are described in Table 2. Fifty-two percent of the patients reached ART clinic within 30 minutes by walk, and little more than half used vehicles. Majority (86.2\%) of them were on ART for more than a year, and approximately two-thirds were on a treatment regimen that requires taking the drugs twice a day.

Table I Sociodemographic and behavioral characteristics of HIV-infected patients on ART and their association with treatment adherence in selected health facilities in Southern Ethiopia, 2014

\begin{tabular}{|c|c|c|c|}
\hline Variable & $\begin{array}{l}\text { Total, } \\
\mathrm{n}\end{array}$ & $\begin{array}{l}\text { Incomplete } \\
\text { adherence, n (\%) }\end{array}$ & $\begin{array}{l}\text { Crude OR } \\
(95 \% \mathrm{CI})\end{array}$ \\
\hline Total & 974 & $122(12.5)$ & - \\
\hline \multicolumn{4}{|l|}{ Age in years $(n=931)$} \\
\hline $15-24$ & 59 & $8(13.6)$ & $2.7(0.9,7.4)$ \\
\hline $25-34$ & 382 & $50(13.1)$ & $2.5(1.2,5.5)^{*}$ \\
\hline $35-44$ & 347 & $45(13.0)$ & $2.5(1.2,5.5)^{*}$ \\
\hline$\geq 45$ & 143 & $8(5.6)$ & Ref \\
\hline \multicolumn{4}{|l|}{$\operatorname{Sex}(n=972)$} \\
\hline Male & 433 & 49 (II.3) & Ref \\
\hline Female & 539 & $73(13.5)$ & $1.2(0.8,1.8)$ \\
\hline \multicolumn{4}{|c|}{ Place of residence $(n=958)$} \\
\hline Urban & 774 & $95(12.3)$ & Ref \\
\hline Rural & 184 & $25(13.6)$ & I.I $(0.7,1.8)$ \\
\hline \multicolumn{4}{|c|}{ Educational status $(\mathrm{n}=969)$} \\
\hline No formal education & 593 & $65(11.0)$ & Ref \\
\hline Formal education & 376 & $57(15.2)$ & $1.5(1.0,2.1)$ \\
\hline \multicolumn{4}{|l|}{ Marital status ( $\mathrm{n}=974$ ) } \\
\hline Currently single & 243 & $36(14.8)$ & $1.6(1.03,2.6)^{*}$ \\
\hline Currently married & 546 & $53(9.7)$ & Ref \\
\hline Not recorded & 185 & $33(17.8)$ & $2.02(1.3,3.2)^{*}$ \\
\hline \multicolumn{4}{|l|}{ Religion ( $n=972$ ) } \\
\hline Protestant Christian & 367 & $65(17.7)$ & $2.8(1.3,6.0)^{*}$ \\
\hline Non-Protestant & 494 & $48(9.7)$ & I.4 $(0.6,3.0)$ \\
\hline \multicolumn{4}{|l|}{ Christian $^{\mathrm{a}}$} \\
\hline Muslim & 111 & $8(7.2)$ & Ref \\
\hline \multicolumn{4}{|c|}{ Current alcohol use $(n=966)$} \\
\hline Yes & $14 \mid$ & $27(19.1)$ & I.8 $(1.2,3.0)^{*}$ \\
\hline No & 825 & 94 (II.4) & Ref \\
\hline \multicolumn{4}{|l|}{ Chat chewing $(n=93 I)$} \\
\hline Current use & 45 & $9(20.0)$ & $1.8(0.8,3.8)$ \\
\hline Past use & 106 & $15(14.2)$ & $1.2(0.7,2.1)$ \\
\hline Never use & 780 & $96(12.3)$ & Ref \\
\hline
\end{tabular}

Notes: ancludes Orthodox and Catholic Christians; *statistically significant.

Abbreviations: ART, antiretroviral therapy; $\mathrm{Cl}$, confidence interval; n, number; OR, odds ratio; Ref, reference category. 
Table 2 Health facility access, social support, and treatment characteristics of HIV-infected patients on ART and their association with treatment adherence in selected health facilities in Southern Ethiopia, June 2014

\begin{tabular}{|c|c|c|c|}
\hline Characteristics & $\begin{array}{l}\text { Total, } \\
\mathrm{n}\end{array}$ & $\begin{array}{l}\text { Incomplete } \\
\text { adherence, } \mathbf{n}(\%)\end{array}$ & $\begin{array}{l}\text { Crude OR } \\
(95 \% \mathrm{Cl})\end{array}$ \\
\hline \multicolumn{4}{|c|}{ Time to reach health facility $(n=942)$} \\
\hline$<30$ minutes & 493 & $60(12.2)$ & Ref \\
\hline$\geq 30$ minutes & 458 & $58(12.7)$ & I.I $(0.7,1.5)$ \\
\hline \multicolumn{4}{|c|}{ Means of transport $(n=960)$} \\
\hline Walking or animal & 423 & $48(11.3)$ & Ref \\
\hline Vehicle & 537 & $7 \mid(13.2)$ & $1.2(0.7,1.8)$ \\
\hline \multicolumn{4}{|c|}{ Assistance to remember medication $(n=940)$} \\
\hline Yes & 701 & $89(12.7)$ & $1.0(0.7,1.6)$ \\
\hline No & 239 & $30(12.6)$ & Ref \\
\hline \multicolumn{4}{|c|}{ Membership in any HIV association $(n=961)$} \\
\hline Yes & 222 & $41(18.5)$ & $1.8(1.2,2.8)^{3}$ \\
\hline No & 739 & $81(11.0)$ & Ref \\
\hline \multicolumn{4}{|c|}{ Treatment duration, months } \\
\hline$\leq 12$ & 132 & $12(9.1)$ & Ref \\
\hline $13-48$ & 384 & $46(12.0)$ & I.4 $(0.7,2.7)$ \\
\hline$\geq 48$ & 443 & $64(14.4)$ & $1.7(0.9,3.2)$ \\
\hline \multicolumn{4}{|l|}{ Treatment regimen } \\
\hline AZT based & 434 & $54(12.4)$ & Ref \\
\hline TDF based & 464 & $61(13.1)$ & I.I $(0.7,1.6)$ \\
\hline Others & 76 & $7(9.2)$ & $0.7(0.3,1.6)$ \\
\hline \multicolumn{4}{|c|}{ Treatment dose per day } \\
\hline Twice daily & 607 & $69(11.4)$ & Ref \\
\hline Once daily & 367 & $53(14.4)$ & $1.3(0.9,1.9)$ \\
\hline
\end{tabular}

Note: *Statistically significant.

Abbreviations: ART, antiretroviral therapy; AZT, zidovudine; $\mathrm{Cl}$, confidence interval; OR, odds ratio; Ref, reference category; TDF, tenofovir.

Psychosocial characteristics and level of knowledge of HIV-infected patients on ART are described in Table 3. Forty-nine percent of the study participants had expressed experience of stigma due to their disease status. Only $25 \%$ had complete knowledge on ART.

The proportion of patients with incomplete adherence was $13 \%$ (95\% CI: $11 \%-15 \%$ ). Of them, $68 \%, 16 \%$, and $16 \%$ missed one, two, and three or more doses, respectively. Age group 25-44 years, currently single, Protestant Christian, alcohol use in the past 1 month, and being a member of the HIV/AIDS association were associated with incomplete adherence in unadjusted analysis (Tables 1-3). In multivariate analysis, being in the age group 25-44 years, being a Protestant Christian, being a member of HIV/AIDS association, consuming alcohol, and being single were associated with incomplete adherence (Table 4).

\section{Discussion}

This study, involving a large number of health facilities from the southern region of Ethiopia, showed that a majority of
Table 3 Psychosocial characteristics and level of knowledge of HIV-infected patients on ART and their association with treatment adherence in selected health facilities in Southern Ethiopia, June 2014

\begin{tabular}{|c|c|c|c|}
\hline Characteristics & $\begin{array}{l}\text { Total, } \\
\text { n }\end{array}$ & $\begin{array}{l}\text { Incomplete } \\
\text { adherence, n (\%) }\end{array}$ & $\begin{array}{l}\text { Crude OR } \\
(95 \% \mathrm{Cl})\end{array}$ \\
\hline \multicolumn{4}{|l|}{ Stigma $(n=97 I)$} \\
\hline Yes & 477 & $54(11.3)$ & Ref \\
\hline No & 466 & $64(13.7)$ & $1.3(0.9,1.8)$ \\
\hline \multicolumn{4}{|l|}{ Depression $(\mathrm{n}=92 \mathrm{I})$} \\
\hline No or minor depression & 252 & $39(15.5)$ & $2.0(0.9,4.7)$ \\
\hline Low depression & 585 & $70(12.0)$ & $1.5(0.7,3.4)$ \\
\hline High depression & 84 & $7(8.3)$ & Ref \\
\hline \multicolumn{4}{|l|}{ Satisfaction to care $(n=956)$} \\
\hline Not satisfied or neutral & 125 & $15(12.0)$ & Ref \\
\hline Satisfied & 831 & $105(12.6)$ & I.I $(0.6,1.9)$ \\
\hline \multicolumn{4}{|l|}{ ART knowledge $(n=954)$} \\
\hline Incomplete knowledge & 716 & $87(12.2)$ & Ref \\
\hline Complete knowledge & 238 & $32(13.4)$ & I.I $(0.7,1.7)$ \\
\hline
\end{tabular}

Abbreviations: ART, antiretroviral therapy; $\mathrm{Cl}$, confidence interval; $n$, number; OR, odds ratio; Ref, reference category.

the patients were adherent to the ART medications. Factors associated with incomplete adherence were young age, being a Protestant Christian, membership in HIV/AIDS association, alcohol consumption, and being single.

Table 4 Multivariate logistic regression analysis of factors associated with incomplete treatment adherence among HIVinfected patients on ART in selected health facilities in Southern Ethiopia, June 2014

\begin{tabular}{|c|c|}
\hline Variables & AOR $(95 \% \mathrm{Cl})$ \\
\hline \multicolumn{2}{|l|}{ Age in years } \\
\hline $15-24$ & $2.1(0.7,6.3)$ \\
\hline $25-34$ & $2.3(I . I, 5.1)^{*}$ \\
\hline $35-44$ & $2.2(1.1,5.0)^{*}$ \\
\hline$\geq 45$ & Ref \\
\hline \multicolumn{2}{|l|}{ Educational status } \\
\hline No formal education & Ref \\
\hline Formal education & $1.4(1.0,2.2)$ \\
\hline \multicolumn{2}{|l|}{ Religion } \\
\hline Protestant Christian & $3.1(1.4,4.1)^{*}$ \\
\hline Non-Protestant Christian ${ }^{\mathrm{a}}$ & $1.5(0.7,3.3)$ \\
\hline Muslim & Ref \\
\hline \multicolumn{2}{|c|}{ Membership in any HIV association } \\
\hline Yes & $1.8(1.2,2.8)^{*}$ \\
\hline No & Ref \\
\hline \multicolumn{2}{|l|}{ Alcohol drinking } \\
\hline Yes & $1.9(1.2,3.2)^{*}$ \\
\hline No & Ref \\
\hline \multicolumn{2}{|l|}{ Marital status } \\
\hline Currently single & $1.7(1.03,2.7)^{*}$ \\
\hline Currently married & Ref \\
\hline Unknown & $1.9(1.2,3.2)^{*}$ \\
\hline \multicolumn{2}{|l|}{ Treatment dose } \\
\hline Once per day & I.4 $(0.9,2.0)$ \\
\hline Twice per day & Ref \\
\hline
\end{tabular}

Notes: ancludes Orthodox and Catholic Christians; *statistically significant. Abbreviations: ART, antiretroviral therapy; AOR, adjusted OR; $\mathrm{Cl}$, confidence interval; OR, odds ratio; Ref, reference category. 
Our study findings on adherence levels are comparable with other studies from Ethiopia. ${ }^{21,22}$ A recent study from Northern Ethiopia reported adherence of $96 \%$ among HIV-infected patients on ART, higher than this study. ${ }^{23}$ The difference might be due to the use of a 30-day recall method for measuring adherence; also the sample population was only from referral hospitals in the previous study. WHO recommends that adherence to ART less than $90 \%$ among HIV-infected persons is an early warning indicator for monitoring emergence and transmission of HIV drug resistance. ${ }^{2}$ However, studies conducted using newer NNRTI (nonnucleoside reverse transcriptase inhibitor) regimens (eg, rilpivirine, etravirine), though unavailable in the current setting, indicated adherence level as low as $85 \%$ could achieve successful viral suppression. ${ }^{24}$ This study with adherence levels marginally less than $90 \%$ without newer nonnucleoside reverse transcriptase inhibitor calls for measures to improve adherence to prevent drug resistance.

In our study, relatively younger age (25-44 years) individuals were more nonadherent to treatment compared with older age group (more than 44 years). Exact reasons for poor adherence were not explored. Previous studies have reported reasons for poor adherence among young people, including denial and fear of HIV infection, low self-esteem, and unstructured and chaotic life styles. ${ }^{25-27}$ Also, a few studies have documented high levels of risky sexual behavior among young age groups on ART. ${ }^{28,29}$ Poor adherence to ART and high-risk sexual behavior among young individuals may increase the spread of drug resistant HIV viruses. Incomplete treatment adherence may also affect future drug choice for such patients for managing treatment failure. The health system should recognize such complex needs of the young age group to design a targeted counseling and support for this high-risk group.

Regarding the association between marital status and adherence, the findings were not consistent across the studies. ${ }^{30}$ In our study, we found an increased risk of incomplete adherence among individuals who were single or not married. Surprisingly, being member of an HIV association was associated with incomplete adherence to treatment. This might have happened because patients with poor adherence were usually advised to be part of such association and this study, being a cross-sectional one, could not establish temporal relations between the two variables.

Studies have reported a statistically significant association between religion and antiretroviral drug adherence. ${ }^{31-35}$ Our study showed that Protestant Christians were more likely to be nonadherent compared to other religions. Qualitative studies may help in finding the contextual reasons behind this difference.

Similar to other studies, alcohol use was associated with incomplete adherence. Previous literature showed that alcohol interacts with ART treatment through both behavioral and physiological pathways. Behaviorally, alcohol use is linked to risky sexual behavior, apart from the poor adherence observed in our study. ${ }^{36}$

We did not find association between psychosocial factors like perceived stigma and depression and knowledge on ART with adherence. Literature reviews also indicated inconsistent findings on the association between these variables, though most publications tend to show the presence of associations..$^{37-40}$

There are few implications for the HIV program. First, the health care providers, especially counselors, should be informed about the high-risk groups for incomplete adherence and appropriately trained to guide these patients. During routine counseling sessions, they can recognize/ identify the high-risk groups and provide focused counseling after exploring the barriers to adherence. Second, existing support systems, like associations for HIV patients, can be strengthened. Innovative approaches like creating medication adherence clubs and mobile phone reminders for the selected high-risk groups can be tried to improve adherence. Third, involving the community leaders, especially religious leaders, may help to reduce this problem.

This study has several strengths. First, the study had a large sample size involving patients from several health facilities. Second, the recall period was shorter than similar studies in Ethiopia, minimizing recall bias, and data collection by a trained health worker from a different health facility may have reduced potential social desirability bias. Third, we comprehensively assessed the factors associated with incomplete adherence including psychosocial and health access factors. There are also a few limitations. The cross-sectional nature of the design does not allow us to establish true cause-effect relations. Furthermore, the level of adherence may be an overestimate because of self-reporting, and we could not validate it using other methods like viral load testing. The response rate in our study is $77 \%$, though those excluded were similar in age and sex distribution. The reasons for providing incomplete questionnaire responses could be withdrawal from the interview after consenting to participate in the study and workload from data collectors, among others. This might still have resulted in over- or underestimation of overall level of adherence. 
In conclusion, around nine out of ten patients on ART adhered to the medication. However, there were certain subgroups with incomplete adherence. Innovative approaches including mobile phone reminders and forming medication adherence clubs could be tried to help improve adherence for patients with the identified risk factors.

\section{Open-access statement}

In accordance with WHO's open-access publication policy for all work funded by WHO or authored/coauthored by WHO staff members, the WHO retains the copyright of this publication through a Creative Commons Attribution IGO license (http://creativecommons.org/licenses/by/3.0/igo/ legalcode) which permits unrestricted use, distribution, and reproduction in any medium provided the original work is properly cited.

\section{Acknowledgment}

This research was conducted through the Structured Operational Research and Training Initiative (SORT IT), a global partnership led by the Special Programme for Research and Training in Tropical Diseases at the World Health Organization (WHO/TDR). The model is based on a course developed jointly by the International Union Against Tuberculosis and Lung Disease (The Union) and Médecins sans Frontières (MSF). The specific SORT IT program which resulted in this publication, was jointly developed and implemented by The Centre for Operational Research, The Union, Paris, France; The Operational Research Unit (LUXOR), Medécins Sans Frontières, Brussels Operational Center, Luxembourg; The Union, South-East Asia Regional Office, New Delhi, India; and The Centre for International Health, University of Bergen, Norway. Finally, we acknowledge the data collectors, ART clinic health workers, and heads of the health facilities for their cooperation during the data collection.

The original study was funded by the Ethiopian Federal HIV/AIDS Prevention and Control Office (FHAPCO). The SORT IT program was supported and funded by Bloomberg Philanthropies, The Union, MSF, the Department for International Development (DFID), UK, and the World Health Organization. La FondationVeuve Emile Metz-Tesch supported open-access publications costs. The funders had no role in study design, data collection, and analysis, decision to publish, or preparation of the manuscript.

\section{Disclosure}

The authors report no conflicts of interest in this work.

\section{References}

1. WHO. Global update on the health sector response to HIV, 2014. Available from: http://www.who.int/hiv/pub/progressreports/update2014/en/. Accessed June 10, 2015.

2. WHO. Using early warning indicators to prevent HIV drug resistance. Available from: http://www.who.int/hiv/pub/meetingreports/ewi_meeting_report/en/. Accessed June 10, 2015.

3. Schaecher KL. The importance of treatment adherence in HIV. Am J Manag Care. 2013;19(12 Suppl):s231-s237.

4. WHO. Guidance on operations and service delivery: adherence to ART 2013. Available from: http://www.who.int/hiv/pub/guidelines/arv2013/ operational/adherence/en/. Accessed July 11, 2014.

5. Reda AA, Biadgilign S. Determinants of adherence to antiretroviral therapy among HIV-infected patients in Africa. AIDS Res Treat. 2012; 2012:574656.

6. Mengistu Z, Chere A. Adherence to antiretroviral therapy and its associated factors among people living with HIV/AIDS in Addis Ababa, Ethiopia. Ethiop Med J. 2012;50(4):355-361.

7. UNAIDS. HIV and AIDS estimates (2013) of Ethiopia. Available from: http://www.unaids.org/en/regionscountries/countries/ethiopia. Accessed June 8, 2015.

8. Arage G, Tessema GA, Kassa H. Adherence to antiretroviral therapy and its associated factors among children at South Wollo Zone Hospitals, Northeast Ethiopia: a cross-sectional study. BMC Public Health. 2014;14:365. doi:10.1186/1471-2458-14-365.

9. Azmeraw D, Wasie B. Factors associated with adherence to highly active antiretroviral therapy among children in two referral hospitals, northwest Ethiopia. Ethiop Med J. 2012;50(2):115-124.

10. Berhe N, Tegabu D, Alemayehu M. Effect of nutritional factors on adherence to antiretroviral therapy among HIV-infected adults: a case control study in Northern Ethiopia. BMC Infect Dis. 2013; 13:233.

11. Kebede A, Wabe NT. Medication adherence and its determinants among patients on concomitant tuberculosis and antiretroviral therapy in South West Ethiopia. N Am J Med Sci. 2012;4(2):67-71.

12. Central Statistical Agency Ethiopia. Annual Statistical Abstract. Available from: http://www.csa.gov.et/. Accessed June 8, 2015.

13. South Region Health Bureau Annual Performance Report. Hawassa, Ethiopia: SNNPR HB, 2013.

14. WHO. Antiretroviral therapy for HIV infection in adults and adolescents recommendations for a public health approach 2010 revision. Available from: http://www.who.int/hiv/pub/arv/adult2010/en/. Accessed July 16, 2014.

15. FMOH. Guidelines for Antiretroviral Treatment in Ethiopia. Addis Ababa, Ethiopia: FMOH; 2008.

16. Adult Adherence to Treatment and Retention in Care/AIDSTAR-One. Available from: http://www.aidstar-one.com/focus_areas/treatment/ resources/technical_briefs/adult_adherence_treatment_and_retention_care. Accessed June 11, 2015.

17. Simoni JM, Kurth AE, Pearson CR, Pantalone DW, Merrill JO, Frick PA. Self-report measures of antiretroviral therapy adherence: a review with recommendations for HIV research and clinical management. AIDS Behav. 2006;10(3):227-245. doi:10.1007/s10461-006-9078-6.

18. Adherence Abstracts/Center for AIDS Prevention Studies (CAPS). Available from: http://caps.ucsf.edu/adherence-abstracts. Accessed June 9, 2015.

19. Berger BE, Ferrans CE, Lashley FR. Measuring stigma in people with HIV: psychometric assessment of the HIV stigma scale. Res Nurs Health. 2001;24(6):518-529.

20. Beck AT, Ward CH, Mendelson M, Mock J, Erbaugh J. An inventory for measuring depression. Arch Gen Psychiatry. 1961;4: $561-571$.

21. Giday A, Shiferaw W. Factors affecting adherence of antiretroviral treatment among AIDS patients in an Ethiopian tertiary university teaching hospital. Ethiop Med J. 2010;48(3):187-194.

22. Mitiku H, Abdosh T, Teklemariam Z. Factors affecting adherence to antiretroviral treatment in harari national regional state, Eastern Ethiopia. ISRN AIDS. 2013;2013:960954 
23. Tsega B, Srikanth BA, Shewamene Z. Determinants of non-adherence to antiretroviral therapy in adult hospitalized patients, Northwest Ethiopia. Patient Prefer Adherence. 2015;9:373-380.

24. Viswanathan S, Justice AC, Alexander GC, et al. Adherence and HIV RNA suppression in the current era of Highly Active Antiretroviral Therapy (HAART). J Acquir Immune Defic Syndr. 2015;69(4):493-498.

25. MacDonell K, Naar-King S, Huszti H, Belzer M. Barriers to medication adherence in behaviorally and perinatally infected youth living with HIV. AIDS Behav. 2013;17(1):86-93. doi:10.1007/s10461-012-0364-1.

26. Rudy BJ, Murphy DA, Harris DR, Muenz L, Ellen J. Prevalence and interactions of patient-related risks for nonadherence to antiretroviral therapy among perinatally infected youth in the United States. AIDS Patient Care STDS. 2010;24(2):97-104.

27. Rudy BJ, Murphy DA, Harris DR, Muenz L, Ellen J. Patient-related risks for nonadherence to antiretroviral therapy among HIV-infected youth in the United States: a study of prevalence and interactions. AIDS Patient Care STDS. 2009;23(3):185-194.

28. Mhalu A, Leyna GH, Mmbaga EJ. Risky behaviours among young people living with HIV attending care and treatment clinics in Dar Es Salaam, Tanzania: implications for prevention with a positive approach. J Int AIDS Soc. 2013;16:17342.

29. Rice E, Batterham P, Rotheram-Borus MJ. Unprotected sex among youth living with HIV before and after the advent of highly active antiretroviral therapy. Perspect Sex Reprod Health. 2006;38(3):162-167.

30. Bhat VG, Ramburuth M, Singh M, et al. Factors associated with poor adherence to anti-retroviral therapy in patients attending a rural health centre in South Africa. Eur J Clin Microbiol Infect Dis. 2010;29(8): 947-953.

31. Finocchario-Kessler S, Catley D, Berkley-Patton J, et al. Baseline predictors of ninety percent or higher antiretroviral therapy adherence in a diverse urban sample: the role of patient autonomy and fatalistic religious beliefs. AIDS Patient Care STDS. 2011;25(2):103-111.
32. Kelly A, Worth H, Man N, et al. Barriers and facilitators for adherence to antiretroviral therapy in Papua New Guinea. Curr HIV Res. 2010;8(8): 630-637.

33. Kisenyi RN, Muliira JK, Ayebare E. Religiosity and adherence to antiretroviral therapy among patients attending a public hospital-based HIV/AIDS clinic in Uganda. J Relig Health. 2013;52(1):307-317.

34. Tumwine $\mathrm{C}$, Neema $\mathrm{S}$, Wagner G. Reasons why high religiosity can coexist with and precipitate discontinuation of anti-retroviral therapy among different HIV clients in Uganda: an exploratory study. Religions. 2012; 3:817-832.

35. Wanyama J, Castelnuovo B, Wandera B, et al. Belief in divine healing can be a barrier to antiretroviral therapy adherence in Uganda. AIDS. 2007;21(11):1486-1487.

36. Schneider M, Chersich M, Temmerman M, Degomme O, Parry CD. The impact of alcohol on HIV prevention and treatment for South Africans in primary healthcare. Curationis. 2014;37(1):1-8.

37. Katz IT, Ryu AE, Onuegbu AG, et al. Impact of HIV-related stigma on treatment adherence: systematic review and meta-synthesis. J Int AIDS Soc. 2013;16(3 Suppl 2):18640.

38. Sayles JN, Wong MD, Kinsler JJ, Martins D, Cunningham WE. The association of stigma with self-reported access to medical care and antiretroviral therapy adherence in persons living with HIV/AIDS. J Gen Intern Med. 2009;24(10):1101-1108.

39. Merten S, Kenter E, McKenzie O, Musheke M, Ntalasha H, MartinHilber A. Patient-reported barriers and drivers of adherence to antiretrovirals in sub-Saharan Africa: a meta-ethnography. Trop Med Int Health. 2010;15(Suppl 1):16-33.

40. Hodgson I, Plummer ML, Konopka SN, et al. A systematic review of individual and contextual factors affecting ART initiation, adherence, and retention for HIV-infected pregnant and postpartum women. PLoS One. 2014;9(11):e111421.
Patient Preference and Adherence

\section{Publish your work in this journal}

Patient Preference and Adherence is an international, peer-reviewed, open access journal that focuses on the growing importance of patient preference and adherence throughout the therapeutic continuum. Patient satisfaction, acceptability, quality of life, compliance, persistence and their role in developing new therapeutic modalities and compounds to optimize

\section{Dovepress}

clinical outcomes for existing disease states are major areas of interest for the journal. This journal has been accepted for indexing on PubMed Central. The manuscript management system is completely online and includes a very quick and fair peer-review system, which is all easy to use. Visit http://www. dovepress.com/testimonials.php to read real quotes from published authors. 